Original article

Paediatrics Today 2014;10(2):112-128

DOI $10.5457 / \mathrm{p} 2005-114.97$

\title{
PEDIATRIC HEALTH-RELATED STRESS, COPING AND QUALITY OF LIFE
}

\author{
Carlos CARONA ${ }^{1,2}$, Neuza SILVA ${ }^{1}$, Helena MOREIRA ${ }^{1}$, Luísa BARROS 3 , \\ Maria Cristina CANAVARRO ${ }^{1}$
}

${ }^{1}$ The University of Coimbra, Coimbra, Portugal, ${ }^{2}$ Coimbra Cerebral Palsy Association, Coimbra, Portugal, ${ }^{3}$ The University of Lisbon, Lisbon, Portugal

Corresponding author:

Carlos Carona

Faculdade de Psicologia e Ciências da

Educação da Universidade de Coimbra

Rua do Colégio Novo Apartado 6153

3001-802 Coimbra

Portugal

ccarona@fpce.uc.pt

Tel.: 239851450

Fax.: 239851465

Received: May 1, 2014

Accepted: July 2, 2014

Copyright (C) 2014 by University Clinical Centre Tuzla. E-mail for permission to publish: paediatricstoday@ukctuzla.ba

\begin{abstract}
Objective - The aim of this study was twofold: first, to compare the experiences of health-related stress and the utilization of coping strategies between pediatric patients with different diagnoses and from distinct age-groups; and second, to examine the associations between the use of specific coping strategies and self-reported pediatric healthrelated quality of life. Materials and methods - 255 children/adolescents with a chronic health condition (asthma, epilepsy or cerebral palsy) were administered the Kidcope and the Disabkids-37 questionnaires. Chi-square tests and multivariate analyses of covariance were conducted to ascertain frequency and mean differences across clinical and developmental groups, and regression analyses were performed to examine associations between variables. Results - The experience of health-related stressors regarding physical limitation was more common for children/adolescents with asthma, while the occurrence of psychosocial stressors was more frequent in children/adolescents with cerebral palsy. There were differences in the utilization of coping strategies to deal with health-related stressors across diagnoses and agegroups, but the most frequently used strategies were consistently assessed as being the most effective. Externalizing emotional regulation was negatively related to the HRQL of pediatric patients with asthma and epilepsy, while self-criticism was negatively associated with the HRQL of children/adolescents with cerebral palsy. Conclusion - The experience of health-related stress, the utilization of coping strategies and their associations with pediatric HRQL are likely to vary across age-groups and diagnoses. Taking into account these developmental and clinical specificities is likely to improve the effectiveness of pediatric stress-coping assessments and interventions.
\end{abstract}

Key words: Pediatric stressors - Developmental coping - Pediatric health outcomes.

\section{Introduction}

Children and adolescents with chronic health conditions not only experience diseaserelated stressors additional to common life stressors $(1,2)$, but are also at greater risk for psychological maladjustment and impaired quality of life than their physically healthy peers $(3,4)$. The ways that children and adolescents cope with health-related stress are likely to influence processes of adaptation to their condition and shape the course and outcomes of their development and maturation $(5,6)$. In the context of a strength-based 
approach to the facilitation of those processes (7), individual competence in dealing with stressful situations is defined as "the effectiveness of the coping responses emitted when an individual is confronted with problematic situations" (p. 215) (8). Therefore, the importance of targeting pediatric health-related stress and coping is twofold: at the individual level, adaptive coping may affect the onset and progression of psychological problems, and promote crucial health behaviors, such as therapeutic adherence; at the societal level, the quality and development of coping in pediatric populations is likely to influence healthcare utilization and long-term consequences in the transition to adulthood (6, 9). Although there is some evidence for the profile of health-related stressors and coping strategies in pediatric populations (2), and for the associations between coping strategies and pediatric health-related quality of life (HRQL) (10), the lack of a systematic study of age and condition-related specificities in pediatric stress, coping and HRQL remains a substantial research gap. Given the fact that pediatric health-related stressors and coping may assume distinctive features across agegroups or different chronic conditions (9), a better understanding of those specificities could improve the effectiveness of assessments and interventions aimed at facilitating pediatric health-related coping and outcomes.

The "disability-stress-coping model" (11) has been widely used as a theoretical framework to guide research on individual and family adaptation to pediatric chronic conditions. In this model, three inter-dynamic levels of variables are distinguished, namely risk factors, resistance factors, and adaptation outcomes. Risk factors include the experience of psychosocial stressors (i.e., handicaprelated problems, major life events, daily hassles) that may be related to disease/disability parameters (e.g., severity, visibility, brain involvement). Resistance factors, on the other hand, comprise stress processing variables, such as the individual's cognitive appraisal and coping strategies. Risk and resistance factors may directly affect adaptation outcomes, as well as the influence of risk factors may be mediated and/or moderated by resistance factors to determine how well a child or adolescent adapts to his/her condition. Since stressors were defined as "problematic situations requiring a solution or some decision-making process for appropriate action" (p. 215) (8), the notion of "health-related stressors" is indeed a terminological specification for referring to stressful events that occur in the context of living with a chronic health condition. Individual stress and coping responses are dependent upon one's cognitive appraisal of the stressful situation (12), and therefore coping responses may be described as "conscious and volitional efforts to regulate emotion, cognition, behavior, physiology, and the environment in response to stressful events or circumstances" (p. 89) (13). At the level of adaptation outcomes, HRQL is defined as "a multidimensional concept that includes the broad areas of functional status, psychological and social well-being, health perceptions, and disease- and treatment-related symptoms" (p. 840) (14), and has emerged as one of the most valued health outcomes in contemporary pediatric research and clinical practice (15).

Although the coping strategies used by children and adolescents with chronic conditions in relation to common stressors tend to be similar to those used by their healthy peers (1), health-related stressors, stress responses and coping may vary significantly across age-groups and clinical conditions (2, 9, 16). Even if the developmental periods of childhood and adolescence share important commonalties, children and adolescents do face distinctive social contexts, maturation issues and developmental tasks $(17,18,19)$, and therefore differences and similarities in pediatric health-related stressors and stress 
responses should be ascertained. As regards the experience of health-related stressors, adolescents tend to emphasize the impact of disease-related problems in their daily lives, while children tend to more often report pain as a health-related stressor (2). Generally, stress responses also seem to vary across age-groups, with adolescents displaying more intense stress reactions to performance and peer rejection stressors than children (20). Coping strategies are also likely to be dependent on the child or adolescent's age $(9,21)$ : older children have been commented to use more strategies that maximize accommodation to the situation, and to find it more effective than younger children; older children also seem to use a greater number and variety of cognitive coping strategies, to focus on positive aspects of the situation, and seek less information (22). This is in agreement with the suggestion that the variety of coping strategies increases in scope and flexibility as children grow up (10). Specifically, two general age trends have been acknowledged in the context of developmental coping across childhood and adolescence: one relates to the increase in coping capacities, such as in support-seeking (from reliance on adults to more self-reliance), problem-solving (from instrumental action to planned problemsolving), and distraction (adding cognitive to behavioral strategies); and another one asserts improvements in the deployment of different coping strategies (increased awareness of the effectiveness of different coping strategies in dealing with specific kinds of stressors) (21).

Complementarily, clinical specificities are equally important: different diagnoses pose a diverse range of stressors and challenges for children and adolescents (5). For instance, in the context of HRQL research, pediatric patients with asthma have been reported to experience greater physical limitation, but a less compromised social quality of life than those with epilepsy $(18,23)$. Moreover, though youngsters with chronic conditions have been reported to have no more problems in their peer relations than other youths, children/ adolescents with conditions that are stigmatizing or that involve the central nervous system have been commented to encounter additional peer difficulties (24). On the topic of pediatric health-related coping, Spirito and colleagues gathered promising evidence for the variability of some coping strategies across illness-related stressors, but failed to detect any significant differences on coping strategy use across diagnostic groups (2).

The association of specific coping strategies with pediatric HRQL outcomes remains understudied, but the available evidence suggests that the strategies of acceptance and distance are positively related to HRQL, while strategies of avoidance, emotional reaction, wishful thinking and cognitive-palliative processing are negatively associated with HRQL, and that the strength of such associations is generally moderate $(10,25)$. Nevertheless, data on the (in)variability of such associations across different diagnoses, while taking into account the potential influence of age on selfreported HRQL (18), is definitely lacking.

For the purpose of the current study, three chronic health conditions were elected because of their elevated prevalences, and distinctive clinical manifestations and related psychosocial challenges. First, while asthma has been identified as the most common pediatric chronic disease (26), epilepsy has been commented as one of the most prevalent neurological conditions in the developing years (27), and cerebral palsy (CP) has been reported as the most common physical disability in childhood (28). Additionally, notwithstanding the fact that asthma and epilepsy share clinical commonalities (i.e., the occurrence of unpredictable episodes that usually require regular medication intake and medical monitoring, and the absence of outwardly observable physical deformities) (23), CP has been described 
as a prototype of childhood disability (29), which is characterized by a distinctive outward visibility of the condition. Moreover, children/adolescents who have conditions that affect the central nervous system, especially seizure disorders, and those who have a long-term physical disability, are at higher risk for psychosocial dysfunction (30).

As a contribution for filling the aforementioned research gaps, the present study had two main objectives. First, we intended to compare: (1) the frequency distribution of health-related stressors; (2) the intensity of health-related stress responses of sadness, anxiety and anger; (3) the frequency of use of specific coping strategies; and (4) the perceived coping efficacy, across different age-groups (children aged 8-12 and adolescents aged 13-18 years) and clinical diagnoses (asthma, epilepsy and CP). Second, we aimed at examining the associations between the use of specific coping strategies and selfreported HRQL in different chronic pediatric health conditions.

\section{Method}

\section{Participants and procedures}

The sample comprised 255 pediatric patients, aged between 8 and 18 years-old, with the clinical diagnosis of a chronic health condition, namely asthma, epilepsy or CP. Using the non-probabilistic convenience sampling method, participants were recruited between March 2009 and July 2011 in the outpatient services of three Portuguese public hospitals (asthma and epilepsy samples) and ten Portuguese Cerebral Palsy Associations (tertiary healthcare institutions enrolled for the collection of the CP sample), after the study had been approved by the institutions' Ethic Committees and/or Direction Boards. For inclusion in the sample, pediatric patients had to meet the following inclusion criteria: (1) age between 8 and 18 years-old; (2) diagno- sis of asthma, epilepsy or CP, established by a physician according to the International Classification of Diseases (ICD-10); (3) minimum time elapsed since diagnosis of one year (for asthma and epilepsy samples); (4) ability to understand and answer the questionnaires (for pediatric patients with CP, data from previous formal assessment of their intelligence quotient [IQ] was collected and a value of 70 was set as the threshold); and (5) absence of comorbidities with any chronic condition elected for the study (e.g., cases of asthma or CP, who also had epilepsy, were excluded).

Informed consents were obtained from all parents and adolescents older than 13, and informal assents were obtained from children. The questionnaires were completed by pediatric patients in a room provided for research purposes in the institution they attended, under the supervision of a trained research assistant.

\section{Measures}

Kidcope. The Kidcope $(31,32)$ is a checklist designed to assess 11 specific cognitive and behavioral coping strategies: distraction ("I did something like watch TV or played a game to forget it"), social withdrawal ("I stayed by myself"), wishful thinking ("I wished I could make things different"), self-criticism ("I blamed myself for causing the problem"), blaming others ("I blamed someone else for causing the problem"), problem-solving ("I tried to fix the problem by thinking of answers"), internalizing emotional regulation ("I tried to calm myself down"), externalizing emotional regulation ("I yelled, screamed, or got mad"), cognitive restructuring ("I tried to see the good side of things"), social support ("I tried to feel better by spending time with others like family, grownups, or friends"), and resignation ("I didn't do anything because the problem couldn't be fixed"). The Kidcope comprises three sections: first, children/adolescents are asked to briefly describe a com- 
mon or a health-related problem/stressor (the latest was asked in this study) they had experienced during the last month; second, they report the intensity of stress responses (in relation to the previously identified problem) within a 5-point Likert scale ranging from 1 (not at all) to 5 (very much), in terms of anxiety ("Did this situation make you feel nervous?"), sadness ("Did this situation make you feel sad?") and anger ("Did this situation make you feel angry?"); third, children/adolescents are asked to rate each of the coping items according to whether they used a given coping strategy (Frequency Scale; "Did you do this?"; response scale: $0=$ "No", 1="Yes"), and how effective they perceived the coping strategy was for them in that specific situation (Efficacy Scale; "How much did it help?"; response scale: $0=$ "Not at all" to $2=$ "A lot"). The Kidcope checklist consists of two versions: a 15-item version for children (each item assessed one coping strategy, except for 4 strategies which were assessed by 2 items); and a 10-item version for adolescents (each item assessed one coping strategy). However, the instrument does allow the conduction of comparisons across age-groups if, as performed in the current study, one single score for each coping strategy (the highest value) is taken into account for the child version. The Kidcope has shown test-retest reliability and concurrent validity (32), and its use has been recommended for pediatric coping and health research $(9,33)$.

Disabkids-37. The self-report version of the chronic-generic module (long version) of Disabkids questionnaires was used to assess pediatric HRQL $(18,34)$. This instrument comprises 37 items addressing six HRQL facets: Independence (e.g., "Are you able to do things without your parents?"), Emotion (e.g., "Are you unhappy because of your condition?"), Inclusion (e.g., "Do your friends enjoy being with you?"), Exclusion (e.g., "Do you feel different from other children/adoles- cents?"), Physical Limitation (e.g., "Is your life ruled by your condition?") and Treatment (e.g., "Does taking medication bother you?"). Those items are to be answered in a 5-point Likert scale ranging from 1 (never) to 5 (always). Since a significant proportion of cases (nearly 25\%) included in this study's sample were not medicated, a standardized global score (0-100) based on the remaining 31 items (after excluding the 6 items of the Treatment facet) was computed, with lower scores indicating the most impaired HRQL. The psychometric quality of Disabkids questionnaires has been established (34), and its use has been recommended for the operationalization of a developmental approach to HRQL assessment (18). The levels of internal consistency observed in the global sample and clinical subsamples used in this study were very good, as shown in Table 3. The Portuguese versions of Disabkids-37 questionnaires included additional questions on relevant clinical and socio-demographic data.

\section{Statistical analyses}

Statistical analyses were performed with the Statistical Package for the Social Sciences (SPSS, v. 20; Chicago, IL, USA). The internal consistency of Disabkids questionnaire was assessed through the calculation of its Cronbach's alphas, which were then classified as acceptable $(\geq 0.70)$ and optimal $(\geq 0.80)$ (35). Descriptive statistics were obtained for clinical and socio-demographic variables and the homogeneity between clinical subsamples was examined through mean differences tests (Student's $t$ tests for independent samples) or frequency distribution differences for categorical variables (chi-square tests). A general qualitative content analysis of health-related stressors reported by children and adolescents was performed, in order to cluster the healthrelated stressors and examine its frequency across age and clinical groups. Differences between age-groups (children aged 8-12 vs. 
adolescents aged 13-18) and clinical conditions (asthma vs. epilepsy vs. CP) on the frequency of health-related stressors and on the frequency of use of specific coping strategies were examined with chi-square tests. Multivariate analyses of covariance (MANCOVA) were performed to examine mean differences on the intensity of stress responses and on the efficacy of coping strategies, between clinical conditions while controlling for age group, and between age groups while controlling for diagnosis. When a multivariate effect was found, subsequent univariate analysis were conducted to examine which specific stress responses and coping strategies significantly differed between groups. Post-hoc analyses were conducted using pairwise comparisons with a Bonferroni correction to control alpha inflation due to multiple testing. Pearson's bivariate correlation coefficients were computed to assess associations between variables, and their strength classified according to the following guidelines: \pm 0.10 to \pm 0.29 (weak); \pm 0.30 to \pm 0.49 (moderate); and \pm 0.50 to \pm 1.0 (strong) (36). Linear regression analyses (method: Enter) were then performed, with patients' age entered in the first block (when significantly correlated with HRQL outcomes), and the frequency of use of coping strategies that correlated significantly with the criterion variable (HRQL) entered in the second block of the regression equation. Effect sizes of main effects derived from these regression analyses were based on the values of $\mathrm{R}^{2}$, which were then classified as small $\left(R^{2} \geq 0.02\right)$, medium $\left(R^{2} \geq 0.13\right)$ and large $\left(R^{2} \geq 0.26\right)$ (37). For all the analyses performed in this study, results were considered statistically significant at a p-value lower than 0.05 .

\section{Results \\ Sample characteristics}

The socio-demographic and clinical characteristics of the global pediatric sample and its clinical subsamples are presented in Table 1 .
Although there were no differences in the frequency distributions of socio-demographic variables (age, gender and SES) between diagnostic subsamples, some clinical differences were detected across diagnoses: presence of comorbid conditions was more frequent in patients with asthma than in those with epilepsy, $\chi_{(1)}^{2}=8.14 ; \mathrm{p}=0.004$, or $\mathrm{CP}, \chi_{(1)}^{2}=9.27$; $\mathrm{p}=0.002$; moreover, regular medication intake was less frequent in patients with $\mathrm{CP}$ than in those with asthma, $\chi_{(1)}^{2}=82.79$; $\mathrm{p}<0.001$, or epilepsy, $\chi_{(1)}^{2}=43.44 ; \mathrm{p}<0.001$. In terms of severity assessment, more than half of the asthma and CP subsamples comprised milder forms of those conditions, while most cases of epilepsy were of mild to moderate severity.

\section{Health-related stressors, stress responses, use and efficacy of coping strategies}

Following a generic content analysis of the health-related stressors reported by children and adolescents, stressors were accordingly classified in four categories (i.e., through thematic aggregation): symptom interference/ physical limitation (e.g., "I had an unexpected attack", "I couldn't do the same things as my classmates in gymnastics"); treatmentrelated stressors (e.g., "I felt bored because having to visit the doctor once again"); psychosocial stressors (e.g., "Other students bullied me") and other stressors (e.g., "I got worried about the evolution of my disease"). Generally, the most frequently self-reported health-related stressors were connected with symptom interference/physical limitation in daily living ( $\mathrm{n}=109,42.7 \%)$, followed by psychosocial stressors $(\mathrm{n}=70,27.5 \%)$ and treatment-related stressors $(\mathrm{n}=39,15.3 \%)$. The most commonly used strategies to cope with health-related stressors broadly portray a flexible coping repertoire, and include cognitive restructuring $(\mathrm{n}=201,78.8 \%)$, dis- 


\section{Table 1 Socio-demographic and clinical characteristics of the sample}

\begin{tabular}{|c|c|c|c|c|}
\hline Characteristics & $\begin{array}{l}\text { Asthma } \\
(\mathrm{n}=111)\end{array}$ & $\begin{array}{l}\text { Epilepsy } \\
(\mathrm{n}=67)\end{array}$ & $\begin{array}{l}\text { CP } \\
(\mathrm{n}=77)\end{array}$ & $\begin{array}{l}\text { Differences between } \\
\text { clinical subsamples }^{f}\end{array}$ \\
\hline Age (M; SD) & $12.51(2.71)$ & $12.51(2.86)$ & $1.82(2.82)$ & $F_{(2,251)}=1.66 ; p=0.192$ \\
\hline Age group (n; \%) & & & & $\chi_{(2)}^{2}=0.31 ; p=0.316$ \\
\hline Children (8-12) & $57(51.4)$ & $29(43.3)$ & $43(55.8)$ & \\
\hline Adolescents (13-18) & $54(48.6)$ & $38(56.7)$ & $34(44.2)$ & \\
\hline Gender (n; \%) & & & & $\chi_{(2)}^{2}=0.50 ; \mathrm{p}=0.779$ \\
\hline Male & $64(57.7)$ & $35(52.2)$ & $43(55.8)$ & \\
\hline Female & $47(42.3)$ & $32(47.8)$ & $34(44.2)$ & \\
\hline $\mathrm{SES}^{\mathrm{a}}(\mathrm{n} ; \%)$ & & & & $\chi_{(4)}^{2}=3.15 ; p=0.534$ \\
\hline Low & $66(59.5)$ & $44(65.7)$ & $46(59.7)$ & \\
\hline Medium & $36(32.4)$ & $18(26.9)$ & $18(23.4)$ & \\
\hline High & $9(8.1)$ & $5(7.5)$ & $10(13.0)$ & \\
\hline Missing & - & - & $3(3.9)$ & \\
\hline Comorbidity (n; \%) & - & - & - & $\chi_{(2)}^{2}=13.33 ; p=0.001$ \\
\hline Yes & $46(41.4)$ & $14(20.9)$ & $15(19.5)$ & \\
\hline No & $64(57.7)$ & $53(79.1)$ & $59(76.6)$ & \\
\hline Missing & $1(0.9)$ & - & $3(3.9)$ & \\
\hline Using medication ( $\mathrm{n} ; \%)$ & - & - & - & $\chi_{(2)}^{2}=98.73 ; \mathrm{p}<0.000$ \\
\hline Yes & 105 (94.6) & $58(86.6)$ & $23(29.9)$ & - \\
\hline No & $6(5.4)$ & $9(13.4)$ & $50(64.9)$ & - \\
\hline Missing & - & - & $4(5.2)$ & - \\
\hline \multicolumn{5}{|l|}{ Asthma severity $^{\mathrm{b}}(\mathrm{n} ; \%)$} \\
\hline Intermittent & $63(56.8)$ & - & - & - \\
\hline Mild persistent & $25(22.5)$ & - & - & - \\
\hline Moderate persistent & $11(9.9)$ & - & - & - \\
\hline Severe persistent & $4(3.6)$ & - & - & - \\
\hline Missing & $8(7.2)$ & - & - & - \\
\hline \multicolumn{5}{|l|}{ Epilepsy severity (n; \%) } \\
\hline Not at all severe & - & $16(23.9)$ & - & - \\
\hline A little severe & - & $15(22.4)$ & - & - \\
\hline Somewhat severe & - & $17(25.4)$ & - & - \\
\hline Moderately severe & - & $14(20.9)$ & - & - \\
\hline Quite severe & - & $2(3.0)$ & - & - \\
\hline Very severe & - & $2(3.0)$ & - & - \\
\hline Extremely severe & - & - & - & - \\
\hline Missing & - & $1(1.5)$ & - & - \\
\hline \multicolumn{5}{|l|}{ CP type $^{\mathrm{d}}(\mathrm{n} ; \%)$} \\
\hline Spastic unilateral & - & - & $34(44.2)$ & - \\
\hline Spastic bilateral & - & - & $34(44.2)$ & - \\
\hline Dyskinetic & - & - & $3(3.9)$ & - \\
\hline Ataxic & - & - & $1(1.3)$ & - \\
\hline Missing & - & - & $5(6.5)$ & - \\
\hline \multicolumn{5}{|l|}{ GMFCS CPe $(\mathrm{n} ; \%)$} \\
\hline I & - & - & $46(59.7)$ & - \\
\hline II & - & - & $11(14.3)$ & - \\
\hline III & - & - & $9(11.7)$ & - \\
\hline IV & - & - & $7(9.1)$ & - \\
\hline V & - & - & $2(2.6)$ & - \\
\hline Missing & - & - & $2(2.6)$ & - \\
\hline
\end{tabular}

${ }^{a}$ Socioeconomic status (SES) was determined using a classification system based on parents' job and educational level (38); ${ }^{\text {b Asthma }}$ severity as assessed by physicians according to the GINA guidelines (39); ' $E p$ ilepsy severity was assessed by physicians using the Global Assessment of Severity of Epilepsy (GASE) Scale (40); ${ }^{\mathrm{d}}$ Classification of CP subtypes according to the Surveillance of CP in Europe project (41); ${ }^{e}$ Levels of function according to the Gross Motor Function Classification System (GMFCS) - Expanded and Revised (42); ${ }^{\mathrm{f}}$ Results of comparison tests for socio-demographic and clinical variables. 
traction ( $\mathrm{n}=194,76.1 \%)$, wishful thinking $(\mathrm{n}=190,74.5 \%)$, problem-solving $(\mathrm{n}=185$, $72.5 \%)$, social support $(\mathrm{n}=171,67.1 \%)$, internalizing emotional regulation $(\mathrm{n}=170$, $66.7 \%)$, resignation $(\mathrm{n}=151,59.2 \%)$, and social withdrawal $(\mathrm{n}=116,45.5 \%)$.

The comparison analyses between agegroups (Table 2) revealed no significant differences on the frequency of self-reported healthrelated stressors $\left(\chi_{(3)}^{2}=2.49 ; \mathrm{p}=0.477\right)$. In addi- tion, no multivariate effects of age-group, while controlling for diagnosis, were found on the intensity of stress responses (Pillai's Trace $=0.02$; $\left.\mathrm{F}_{(3,242)}=1.29 ; \mathrm{p}=0.280 ; \mathrm{y}_{\mathrm{p}}{ }^{2}=0.016\right)$.

However, the use of specific coping strategies was variant across age-groups: when compared to adolescents, children reported higher utilization of distraction, social withdrawal, problem solving, internalizing emotional regulation, wishful thinking and social support; on

\begin{tabular}{|c|c|c|c|}
\hline & $\begin{array}{l}\text { Children } \\
(\mathrm{n}=129)\end{array}$ & $\begin{array}{l}\text { Adolescents } \\
(\mathrm{n}=126)\end{array}$ & Differences between age groups \\
\hline Health-related stressor $(\mathrm{n} ; \%)$ & & & $\chi_{(3)}^{2}=2.49 ; p=0.477$ \\
\hline Symptom interference/ Physical limitation & $59(45.7)$ & $50(39.7)$ & - \\
\hline Treatment-related stressors & $16(12.4)$ & $23(18.3)$ & - \\
\hline Psychosocial stressors & $37(28.7)$ & $33(26.2)$ & - \\
\hline Others & $5(3.9)$ & $7(5.6)$ & - \\
\hline Missing & $12(9.3)$ & $13(10.3)$ & - \\
\hline \multicolumn{4}{|l|}{ Stress responses $(\mathrm{M} ; \mathrm{SD})$} \\
\hline Sadness & $2.36(1.35)$ & $2.41(1.23)$ & $F_{(1,244)}=0.23 ; p=0.631 ; \mathrm{y}_{\mathrm{p}}{ }^{2}=0.001$ \\
\hline Anxiety & $2.50(1.33)$ & $2.64(1.13)$ & $\mathrm{F}_{(1,244)}=1.09 ; \mathrm{p}=0.298 ; \mathrm{y}_{\mathrm{p}}^{2}=0.004$ \\
\hline Anger & $2.12(1.40)$ & $2.40(1.29)$ & $\mathrm{F}_{(1,244)}=3.09 ; \mathrm{p}=0.080 ; \mathrm{y}_{\mathrm{p}}^{2}=0.013$ \\
\hline \multicolumn{4}{|l|}{ Use of coping strategies ( $\mathrm{n} ; \%)$} \\
\hline Distraction & $110(85.3)$ & $84(66.7)$ & $\chi_{(1)}^{2}=11.49 ; \mathrm{p}<0.001$ \\
\hline Social withdrawal & $80(62.0)$ & $36(28.6)$ & $\chi_{(1)}^{2}=28.75 ; \mathrm{p}<0.001$ \\
\hline Cognitive restructuring & $106(82.2)$ & $95(75.4)$ & $\chi^{2}=2.12 ; \mathrm{p}=0.146$ \\
\hline Self-criticism & $24(18.6)$ & $27(21.4)$ & $\chi_{(1)}^{2}=0.32 ; \mathrm{p}=0.573$ \\
\hline Blaming others & $16(12.4)$ & $21(16.7)$ & $\chi_{(1)}^{2}=0.99 ; \mathrm{p}=0.321$ \\
\hline Problem-solving & $110(85.3)$ & $75(59.5)$ & $\chi_{(1)}^{2}=1.22 ; \mathrm{p}<0.001$ \\
\hline Emotional regulation (externalizing) & $21(16.3)$ & $15(11.9)$ & $\chi_{(1)}^{2}=1.01 ; p=0.316$ \\
\hline Emotional regulation (internalizing) & $99(76.7)$ & $71(56.3)$ & $\chi_{(1)}^{2}=2.64 ; \mathrm{p}<0.001$ \\
\hline Wishful thinking & $109(84.5)$ & $81(64.3)$ & $\chi_{(1)}^{2}=15.02 ; \mathrm{p}<0.001$ \\
\hline Social support & $102(79.1)$ & $69(54.8)$ & $\chi_{(1)}^{2}=16.44 ; \mathrm{p}<0.001$ \\
\hline Resignation & $51(3.9)$ & $100(79.4)$ & $\chi^{2}=43.12 ; \mathrm{p}<0.001$ \\
\hline \multicolumn{4}{|l|}{ Coping efficacy (M; SD) } \\
\hline Distraction & $1.28(0.82)$ & $1.04(0.89)$ & $F_{(1,244)}=4.63 ; p=0.032 ; y_{p}^{2}=0.019$ \\
\hline Social withdrawal & $0.79(0.89)$ & $0.31(0.67)$ & $\mathrm{F}_{(1,244)}=22.27 ; \mathrm{p}<0.001 ; \mathrm{y}_{\mathrm{p}}^{2}=0.084$ \\
\hline Cognitive restructuring & $1.38(0.85)$ & $1.20(0.83)$ & $F_{(1,244)}=3.16 ; p=0.077 ; y_{p}^{2}=0.013$ \\
\hline Self-criticism & $0.22(0.58)$ & $0.26(0.63)$ & $\mathrm{F}_{(1,244)}=0.39 ; \mathrm{p}=0.534 ; \mathrm{\eta}_{\mathrm{p}}{ }^{2}=0.002$ \\
\hline Blaming others & $0.19(0.58)$ & $0.18(0.48)$ & $\mathrm{F}_{(1,244)}=0.01 ; \mathrm{p}=0.940 ; \mathrm{y}_{\mathrm{p}}^{2}=0.000$ \\
\hline Problem-solving & $1.46(0.77)$ & $0.91(0.90)$ & $F_{(1,244)}=26.57 ; p<0.001 ; y_{p}^{2}=0.098$ \\
\hline Emotional regulation (externalizing) & $0.17(0.50)$ & $0.10(0.39)$ & $F_{(1,244)}=1.38 ; p=0.242 ; y_{p}^{2}=0.006$ \\
\hline Emotional regulation (internalizing) & $1.27(0.86)$ & $0.94(0.93)$ & $\mathrm{F}_{(1,244)}=8.30 ; \mathrm{p}=0.004 ; \mathrm{y}_{\mathrm{p}}^{2}=0.033$ \\
\hline Wishful thinking & $1.21(0.85)$ & $0.63(0.76)$ & $\mathrm{F}_{(1,244)}=30.60 ; \mathrm{p}<0.001 ; \mathrm{y}_{\mathrm{p}}{ }^{2}=0.111$ \\
\hline Social support & $1.41(0.87)$ & $0.96(0.93)$ & $\mathrm{F}_{(1,244)}=15.28 ; \mathrm{p}<0.001 ; \mathrm{y}_{\mathrm{p}}{ }^{2}=0.059$ \\
\hline Resignation & $0.49(0.78)$ & $1.10(0.82)$ & $F_{(1.244)}=35.42 ; p<0.001 ; \mathrm{y}_{\mathrm{v}}{ }^{2}=0.127$ \\
\hline
\end{tabular}


the other hand, in comparison with children, the use of resignation was more frequently reported by adolescents. Regarding the perceived efficacy of coping strategies, the multivariate effect of age-group was also significant, Pillai's Trace $=0.31 ; \quad \mathrm{F}_{(11,234)}=9.46 ; \mathrm{p}<0.001$; $\mathrm{y}_{\mathrm{p}}{ }^{2}=0.308$. The subsequent univariate analyses, presented in Table 2, indicated that children perceived distraction, social withdrawal, problem-solving, internalizing emotional regulation, wishful thinking and social support as more effective coping strategies than did adolescents, and, conversely, adolescents reported higher efficacy for resignation.

Regarding between-groups comparisons across clinical diagnoses (Table 3), significant differences were found on the frequency of self-reported health-related stressors: children/adolescents with asthma reported more symptom interference/physical limitation problems, but less psychosocial stressors than children/adolescents with epilepsy, $\chi_{(3)}^{2}=43.44 ; \mathrm{p}<0.001$; on the other hand, in comparison with children/ adolescents with CP, pediatric patients with asthma, $\chi_{(3)}^{2}=63.69 ; \mathrm{p}<0.001$, or epilepsy, $\chi_{(3)}^{2}=11.22 ; \mathrm{p}=0.011$, reported a greater occurrence of symptom interference/physical limitation stressors, but fewer experiences of psychosocial stressors. Controlling for children's age group, the MANCOVA presented a significant multivariate effect of diagnosis on the intensity of stress responses, Pillai's Trace $=0.06 ; \mathrm{F}_{(6,484)}=2.48 ; \mathrm{p}=0.022$; $\mathrm{y}_{\mathrm{p}}{ }^{2}=0.030$. The univariate effects for sadness, anxiety and anger responses are presented in Table 3. The post-hoc comparison analyses revealed that children/adolescents with $\mathrm{CP}$ reported more intense responses of sadness (mean difference $=0.60 ; \mathrm{SE}=0.20 ; \mathrm{p}=0.007$ ) and anger (mean difference $=0.36 ; \mathrm{SE}=0.20$; $\mathrm{p}=0.029$ ) than children/adolescents with asthma; and children/adolescents with $\mathrm{CP}$ and epilepsy reported more intense responses of anxiety than paediatric asthma patients (mean difference $=0.65 ; \mathrm{SE}=0.19 ; \mathrm{p}=0.002$; and mean difference $=0.46 ; \quad S E=0.19$; $\mathrm{p}=0.045$, respectively).

The utilization of health-related coping strategies was also variant across clinical diagnoses: asthma patients reported less use of distraction than their peers with epilepsy, $\chi_{(1)}^{2}=4.92 ; \mathrm{p}=0.046$, or $\mathrm{CP}, \chi_{(1)}^{2}=4.92$; $\mathrm{p}=0.027$; social withdrawal was more frequently used by children/adolescents with CP, than by their peers with asthma, $\chi_{(1)}^{2}=17.87$; $\mathrm{p}<0.001$, or epilepsy, $\chi_{(1)}^{2}=4.38 ; \mathrm{p}=0.036$; selfcriticism was more commonly used as a coping strategy by patients with epilepsy than by patients with asthma, $\chi_{(1)}^{2}=10.59 ; \mathrm{p}=0.001$; children/adolescents with asthma reported blaming less the others as a mean of coping than their peers with epilepsy, $\chi_{(1)}^{2}=8.55$; $\mathrm{p}=0.003$, or $\mathrm{CP}, \chi_{(1)}^{2}=9.09 ; \mathrm{p}=0.003$; wishful thinking was more frequently used as a coping strategy by children/adolescents with $\mathrm{CP}$ than their peers with asthma, $\chi_{(1)}^{2}=6.49$; $\mathrm{p}=0.011$; and finally, pediatric patients with epilepsy reported greater use of resignation than pediatric patients with $\mathrm{CP}, \chi_{(1)}^{2}=9.81$; $\mathrm{p}=0.002$. As regards to the efficacy of coping strategies, the multivariate effect of clinical condition was also significant, Pillai's Trace $=0.20 ; \quad \mathrm{F}_{(22,468)}=2.33 ; \mathrm{p}=0.001 ; \mathrm{y}_{\mathrm{p}}{ }^{2}=0.099$. As presented in Table 3, we found significant differences in the efficacy of four coping strategies: social withdrawal, self-criticism, blaming others and resignation. Specifically, social withdrawal was considered more effective by children/adolescents with CP than by patients with asthma (mean difference $=0.34$; $\mathrm{SE}=0.12 ; \mathrm{p}=0.012$ ); and children/adolescents with epilepsy reported greater efficacy for selfcriticism, when compared to their peers with asthma (mean difference $=0.27 ; \quad S E=0.09$; $\mathrm{p}=0.013$ ) or $\mathrm{CP}$ (mean difference $=0.26$; $\mathrm{SE}=0.10 ; \mathrm{p}=0.035$ ), for blaming others, when compared to children/adolescents with asthma (mean difference $=0.30 ; \quad S E=0.08$; $\mathrm{p}=0.001$ ), and for resignation, when com- 


\begin{tabular}{|c|c|c|c|c|}
\hline & $\begin{array}{l}\text { Asthma } \\
(\mathrm{n}=111)\end{array}$ & $\begin{array}{l}\text { Epilepsy } \\
(\mathrm{n}=67)\end{array}$ & $\begin{array}{l}\mathrm{CP} \\
(\mathrm{n}=77)\end{array}$ & Differences between diagnoses \\
\hline Health-related stressor (n; \%) & & & & $\chi_{(6)}^{2}=73.93 ; \mathrm{p}<0.001$ \\
\hline $\begin{array}{l}\text { Symptom interference/Physical } \\
\text { limitation }\end{array}$ & $76(68.5)$ & $21(31.3)$ & $12(15.6)$ & \\
\hline Treatment-related stressors & $16(14.4)$ & $17(25.4)$ & $6(7.8)$ & - \\
\hline Psychosocial stressors & $9(8.1)$ & $23(34.3)$ & $38(49.4)$ & - \\
\hline Others & $2(1.8)$ & $5(7.5)$ & $5(6.5)$ & - \\
\hline Missing & $8(7.2)$ & $1(1.5)$ & $16(20.8)$ & - \\
\hline \multicolumn{5}{|l|}{ Stress responses $(\mathrm{M} ; \mathrm{SD})$} \\
\hline Sadness & $2.13(1.16)$ & $2.46(1.36)$ & $2.72(1.36)$ & $\mathrm{F}_{(2,243)}=4.92 ; \mathrm{p}=0.008 ; \mathrm{y}_{\mathrm{p}}^{2}=0.039$ \\
\hline Anxiety & $2.26(1.09)$ & $2.73(1.24)$ & $2.90(1.36)$ & $\mathrm{F}_{(2,243)}=.86 ; \mathrm{p}=0.001 ; \mathrm{y}_{\mathrm{p}}{ }^{2}=0.053$ \\
\hline Anger & $2.01(1.18)$ & $2.39(1.40)$ & $2.51(1.50)$ & $\mathrm{F}_{(2,243)}=3.73 ; \mathrm{p}=0.025 ; \mathrm{y}_{\mathrm{p}}{ }^{2}=0.030$ \\
\hline \multicolumn{5}{|l|}{ Use of coping strategies ( $\mathrm{n} ; \%)$} \\
\hline Distraction & $76(68.5)$ & $55(82.1)$ & $63(81.8)$ & $\chi_{(2)}^{2}=6.85 ; p=0.033$ \\
\hline Social withdrawal & $36(32.4)$ & $31(46.3)$ & $49(63.6)$ & $\chi_{(2)}^{2}=17.87 ; \mathrm{p}<0.001$ \\
\hline Cognitive restructuring & $92(82.9)$ & $54(80.6)$ & $55(71.4)$ & $\chi_{(2)}^{2}=3.14 ; p=0.208$ \\
\hline Self-criticism & $14(12.6)$ & $22(32.8)$ & $15(19.5)$ & $\chi_{(2)}^{2}=10.70 ; p=0.005$ \\
\hline Blaming others & $7(6.3)$ & $14(20.9)$ & $16(20.8)$ & $\chi_{(2)}^{2}=10.81 ; \mathrm{p}=0.004$ \\
\hline Problem-solving & $80(72.1)$ & 48 (71.6) & $57(74.0)$ & $\chi_{(2)}^{2}=0.13 ; p=0.940$ \\
\hline Emotional regulation (externalizing) & $12(10.8)$ & $12(17.9)$ & $12(15.6)$ & $\chi_{(2)}^{2}=1.93 ; p=0.380$ \\
\hline Emotional regulation (internalizing) & $73(63.8)$ & $40(59.7)$ & $57(74.0)$ & $\chi_{(2)}^{2}=3.01 ; \mathrm{p}=0.222$ \\
\hline Wishful thinking & $74(66.7)$ & $53(79.1)$ & $63(81.8)$ & $\chi_{(2)}^{2}=7.40 ; p=0.025$ \\
\hline Social support & $72(64.9)$ & $49(73.1)$ & $50(64.9)$ & $\chi_{(2)}^{2}=0.42 ; p=0.493$ \\
\hline Resignation & $66(59.5)$ & $49(73.1)$ & $36(46.8)$ & $\chi_{(2)}^{2}=9.81 ; p=0.007$ \\
\hline \multicolumn{5}{|l|}{ Coping efficacy (M; SD) } \\
\hline Distraction & $1.08(0.89)$ & $1.22(0.84)$ & $1.23(0.82)$ & $\mathrm{F}_{(2,243)}=0.85 ; \mathrm{p}=0.430 ; \mathrm{y}_{\mathrm{p}}^{2}=0.007$ \\
\hline Social withdrawal & $0.39(0.72)$ & $0.61(0.87)$ & $0.76(0.89)$ & $\mathrm{F}_{(2,243)}=4.79 ; \mathrm{p}=0.009 ; \mathrm{y}_{\mathrm{p}}^{2}=0.038$ \\
\hline Cognitive restructuring & $1.42(0.81)$ & $1.22(0.84)$ & $1.18(0.88)$ & $\mathrm{F}_{(2,243)}=2.35 ; \mathrm{p}=0.098 ; \mathrm{y}_{\mathrm{p}}^{2}=0.019$ \\
\hline Self-criticism & $0.17(0.52)$ & $0.44(0.75)$ & $0.18(0.53)$ & $\mathrm{F}_{(2,243)}=4.73 ; \mathrm{p}=0.010 ; \mathrm{y}_{\mathrm{p}}^{2}=0.037$ \\
\hline Blaming others & $0.06(0.31)$ & $0.36(0.74)$ & $0.22(0.53)$ & $\mathrm{F}_{(2,243)}=6.70 ; \mathrm{p}=0.001 ; \mathrm{y}_{\mathrm{p}}{ }^{2}=0.052$ \\
\hline Problem-solving & $1.13(0.87)$ & $1.14(0.91)$ & $1.32(0.86)$ & $F_{(2,243)}=0.83 ; p=0.438 ; y_{p}^{2}=0.007$ \\
\hline Emotional regulation (externalizing) & $0.09(0.40)$ & $0.20(0.54)$ & $0.14(0.45)$ & $\mathrm{F}_{(2,243)}=1.33 ; \mathrm{p}=0.266 ; \mathrm{y}_{\mathrm{p}}{ }^{2}=0.011$ \\
\hline Emotional regulation (internalizing) & $1.15(0.93)$ & $0.98(0.93)$ & $1.16(0.86)$ & $\mathrm{F}_{(2,243)}=0.56 ; \mathrm{p}=0.570 ; \mathrm{y}_{\mathrm{p}}^{2}=0.005$ \\
\hline Wishful thinking & $0.81(0.87)$ & $1.00(0.87)$ & $1.03(0.83)$ & $\mathrm{F}_{(2,243)}=2.04 ; \mathrm{p}=0.133 ; \mathrm{y}_{\mathrm{p}}^{2}=0.016$ \\
\hline Social support & $1.17(0.94)$ & $1.25(0.91)$ & $1.16(0.94)$ & $\mathrm{F}_{(2,243)}=0.50 ; \mathrm{p}=0.605 ; \mathrm{y}_{\mathrm{p}}{ }^{2}=0.004$ \\
\hline Resignation & $0.79(0.82)$ & $1.08(0.90)$ & $0.54(0.80)$ & $\mathrm{F}_{(2.243)}=5.94 ; \mathrm{p}=0.003 ; \mathrm{j}_{\mathrm{p}}{ }^{2}=0.047$ \\
\hline
\end{tabular}

pared to children/adolescents with CP (mean difference $=0.46 ; \mathrm{SE}=0.13 ; \mathrm{p}=0.002)$.

\section{Health-related coping strategies as correlates of pediatric HRQL}

Generally, the observed significant correlations between the coping strategy use and HRQL outcomes had a negative direction and, when considering the global sample with no diagnostic stratification, the strength of those associations was weak, with HRQL being negatively correlated with the use of distraction, social withdrawal, self-criticism, blaming others, externalizing emotional regulation and wishful thinking, to deal with health-related stressors (see Table 4). However, when considering diagnostic subsamples, distinctive results did emerge: for asthma, distraction, social withdrawal, blam- 
ing others, problem-solving, externalizing emotional regulation and wishful thinking were negative and weakly related to HRQL; for epilepsy, self-criticism and blaming others were negatively and weakly associated with
HRQL, but social withdrawal and externalizing emotional regulation were moderately associated with HRQL in the same direction; for $\mathrm{CP}$, cognitive restructuring and self-criticism were positively and negatively correlated

Table 4 Matrix of inter-correlations between coping strategies used by pediatric patients for health-related stressors and their self-reported HRQL

\begin{tabular}{lllll}
\hline & HRQL & & & \\
\cline { 2 - 4 } & Global sample & Asthma & Epilepsy & CP \\
\hline Child's age & 0.08 & 0.05 & $0.33^{* *}$ & $-19^{\dagger}$ \\
Distraction $^{\mathrm{a}}$ & $-0.12^{*}$ & $-0.25^{* *}$ & 0.07 & 0.01 \\
Social withdrawal $^{\mathrm{a}}$ & $-0.27^{* *}$ & $-0.23^{*}$ & $-0.37^{* *}$ & -0.07 \\
Cognitive restructuring $^{\mathrm{a}}$ & 0.09 & 0.01 & -0.03 & $0.22^{\dagger}$ \\
Self-criticism $^{\mathrm{a}}$ & $-0.21^{* *}$ & -0.04 & $-0.27^{*}$ & $-24^{*}$ \\
Blaming others $^{\mathrm{a}}$ & $-0.21^{* *}$ & $-0.19^{*}$ & $-0.29^{*}$ & -0.04 \\
Problem-solving $^{\mathrm{a}}$ & -0.06 & $-0.20^{*}$ & 0.01 & 0.07 \\
Emotional regulation (externalizing) $^{\mathrm{a}}$ & $-0.24^{* *}$ & $-0.29^{* *}$ & $-0.42^{* *}$ & 0.02 \\
Emotional regulation (internalizing) $^{\mathrm{a}}$ & 0.01 & -0.15 & 0.10 & 0.16 \\
Wishful thinking $^{\mathrm{a}}$ & $-0.19^{* *}$ & $-0.23^{*}$ & -0.11 & -0.09 \\
Social support $^{\mathrm{a}}$ & 0.02 & -0.11 & 0.14 & 0.10 \\
Resignation $^{\mathrm{a}}$ & 0.01 & -0.06 & 0.09 & -0.01 \\
\hline Internal Consistency Levels $[\alpha]^{\text {a }}$ & 0.91 & 0.92 & 0.92 & 0.89 \\
\hline
\end{tabular}

aUse of coping strategy: $0-\mathrm{No} ; 1-$ Yes. ${ }^{*} \mathrm{p} \leq 0.05,{ }^{* *} \mathrm{p} \leq 0.01,{ }^{\dagger} \mathrm{p} \leq 0.10$.

Table 5 Regression analyses (main effects of HRQL regressed on child's age and coping strategies) for global and pediatric subsamples

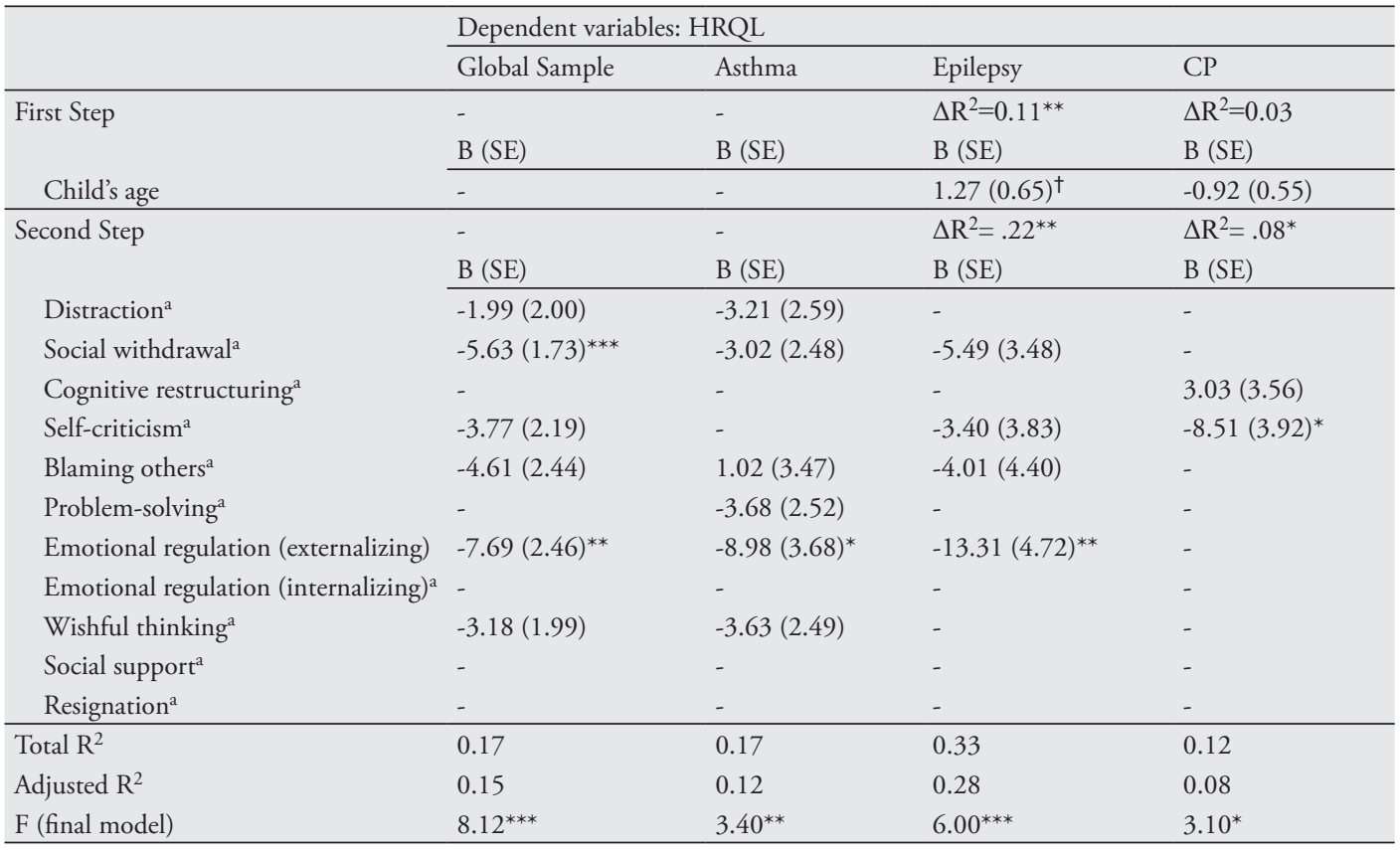

aUse of coping strategy: $0-$ No; 1 - Yes. ${ }^{*} \mathrm{p}<0.05 ;{ }^{* *} \mathrm{p}<0.01 ;{ }^{* * *} \mathrm{p}<0.001 ;{ }^{\dagger} \mathrm{p}=0.06$. 
with HRQL, respectively, and the strength of that association was weak. Curiously enough, patients' age was significantly correlated with HRQL only in the context of neurodevelopmental conditions, but while for epilepsy that association was moderate and positive, for CP it was weak and negative.

Subsequently, taking into account the whole sample, regression analyses confirmed significant, medium negative main effects of social withdrawal and externalizing emotional regulation on pediatric $\mathrm{HRQL}, \mathrm{F}_{(6,244)}=8.12$, $\mathrm{p}<0.001, \mathrm{R}^{2}=0.17$. For asthma, specifically, externalizing emotional regulation was the only significant predictor of HRQL, with a medium-sized negative main effect, $\mathrm{F}_{(6,103}=3.40$, $\mathrm{p}<0.01, \mathrm{R}^{2}=0.17$. For epilepsy, on the other hand, externalizing emotional regulation, this time along with patient's age, displayed a large main effect on pediatric $\mathrm{HRQL}, \mathrm{F}_{(5,61)}=5.99$, $\mathrm{p}<0.001, \mathrm{R}^{2}=0.33$. Finally, as regards $\mathrm{CP}$, selfcriticism was significantly and negatively related to HRQL, even if that main effect was small-sized, $\mathrm{F}_{(3,71)}=3.10, \mathrm{p}<0.05, \mathrm{R}^{2}=0.12$ (see Table 5).

\section{Discussion}

This study investigated health-related stress and coping appraisals in children and adolescents with a chronic health condition, and examined the links between the use of specific coping strategies to deal with healthrelated stressors and self-reported pediatric quality of life. The study's main findings add critical evidence for the need to attend to developmental and clinical diagnostic specificities in pediatric stress and coping assessment, research and intervention, since the unstratified clustering of those phenomena may obscure vital differences and reduce the effectiveness of such practices.

Firstly, there were no age-group differences in the experience of health-related stressors, although these varied across diagnoses.
This suggests that the type of health-related stressors faced by pediatric patients may vary according to the challenges posed by a given diagnosis to a larger extent than to those posed by different developmental periods. In agreement with previous studies $(18,23)$, children/adolescents with asthma reported more physical limitation/symptom interference problems than their peers with epilepsy. However, even if those stressors were more common in the lives of patients with asthma or epilepsy in comparison with children/adolescents with CP, the latest group reported the highest occurrence of psychosocial stressors, such as being bullied and other peer problems. Since most cases of the CP sample were in fact milder forms of that condition, the observed result is aligned with previous reports of a more impaired quality of life, especially in the social domain, for less severely impaired children with CP (43). Moreover, these children/adolescents with disabilities that are not always obvious or visible to others may lack social support and be at heightened risk of being bullied (44).

The experience of health-related stress responses also differed between diagnoses: children/adolescents with CP reported higher levels of sadness, anxiety and anger, than their peers with asthma, and patients with a neurodevelopmental condition reported more intense responses of anxiety than patients with asthma. These results could translate the assertion that children/adolescents who have chronic conditions that affect the central nervous system or a long-term physical disability may be at increased risk for psychological problems (30); in fact, CP is a chronic health condition that combines those two risk factors, and thus the experience of health-related distress may be heightened in this group.

On the topic of coping strategies used by pediatric patients to deal with health-related stressors, there was a general tendency for children/adolescents to report a more fre- 
quent use of some coping strategies that are typically clustered as "positive/approaching", as opposite to "negative/avoidant" (9, 45), such as cognitive restructuring, problemsolving, internalizing emotional regulation and social support. Nevertheless, "negative/ avoidant" strategies, such as distraction, wishful thinking and resignation, were also among the most common coping responses, thus contributing for the portrayal of a broad, flexible coping repertoire for pediatric populations. Interestingly, the most frequently used coping strategies were equally assessed as the most effective by children and adolescents to deal with health-related stressors across different diagnoses. This consistency between coping strategies utilization and their perceived effectiveness may well depict the resilience process underlying developmental health-related coping, while underlining the relevance of assessing pediatric coping from a situational point of view.

Nonetheless, the following developmental differences between age-groups in the use of health-related coping strategies were detected: on the one hand, children reported greater use of a variety of coping strategies (including distraction, isolation, problem solving, internalizing emotional regulation, wishful thinking and social support), but on the other hand, adolescents reported higher utilization of resignation as a coping strategy. Generally, these results may reflect the developmental trend of improvements in the deployment of different coping strategies (21), which is revealed in a more effective selection of coping behaviors in dealing with specific kind of stressors. Concordantly, children/ adolescents in this study were asked to specifically report and reflect on a given healthrelated stressor, and not on any common or prototype stressor. As regards the preferred use of resignation by adolescents, it is noteworthy that "resignation" as a coping strategy was assessed in this study with an item that could imply a negative tendency to either dissociate or behaviourally disengage from the situation, or on the other hand, a positive approach to willingly accept the difficult situation and adopt a non-reactive mindful attitude (e.g., "I just accepted the problem because I knew I couldn't do anything about it."). This particular observation suggests either the need to reformulate that specific item in Kidcope checklists in order to clarify its meaning, or to complementary conduct clinical interviews to enrich and improve pediatric coping assessment procedures. Additionally, recent studies observed that adolescents with a chronic condition reported a better HRQL in the mental and social facets, but a worse HRQL in the physical/treatment facet, if compared with younger pediatric patients (18). Therefore, additional caution should be taken in assuming the preferred used of resignation by adolescents, as a strictly positive or negative coping behaviour in dealing with health-related stressors.

Complementarily to those developmental specificities, differences in the use of coping strategies between diagnoses were small-sized but theoretically consistent: social withdrawal, which has been identified as one of the most common behavioral problems in school-aged children with CP (46), was more frequently used by children/adolescents with CP than by their peers with asthma or epilepsy; accordingly, pediatric patients with a neurodevelopmental condition (i.e., epilepsy or $\mathrm{CP}$ ) reported blaming others more often than children/adolescents with asthma, and such preferred use could be hypothetically understood as an immediate response to discrimination, bullying, stigma or social putdown, which tend to occur more frequently in the context of these conditions $(44,47)$.

The assessment of subjective appraisals of coping efficacy revealed medium-sized differences across clinical conditions, and these were more pronounced for children/adoles- 
cents with epilepsy, who perceived self-criticism as more effective than pediatric patients with asthma or CP. Children/adolescents with epilepsy also perceived blaming others and resignation as more effective coping responses, than their peers with asthma and $\mathrm{CP}$, respectively. These specific coping differences may be understood within the social context of this disease: "from ancient to modern times, a diagnosis of epilepsy has carried with it an associated social stigma that affects people with epilepsy in ways beyond simply having to cope with their neurological disorder." (p. 112) (48). For instance, it has been ascertained that people who experience significant social put-down, are prone to exhibit higher levels of self-blame and self-criticism (49) and this could be the case for the clinical group of pediatric epilepsy.

Overall, significant main effects were observed for the use of coping strategies of social withdrawal and externalizing emotional regulation on self-reported HRQL of pediatric patients in general. Specifically, externalizing emotional regulation was negatively linked with the HRQL of children/adolescents with asthma and epilepsy, though the magnitude of such main effect (along with child's age) was larger for the latest clinical group. This overall result is aligned with previous reports of negative associations between the use of externalizing emotional reaction as a coping strategy and the HRQL of pediatric patients with different chronic health conditions (10, 25), and thus adds evidence for the distinctive influence that such coping response may assume in the general context of pediatric stress-coping processes. Finally, self-criticism was the only coping strategy that significantly predicted HRQL for the CP sample, even if that effect was small-sized. Interestingly, patient's age correlated distinctively with HRQL in different clinical subsamples: while the direction of that association was positive for epilepsy, it was negative for CP. These results suggest that the patient's age should be taken in account when examining HRQL outcomes for pediatric populations, since age may be related to positive adaptation in some conditions, or health deterioration in others.

Despite the contributions brought by the present study, its results should be read under the consideration of a number of limitations. First, its sample was collected in distinct health settings, such as public central hospitals and tertiary healthcare institutions, thus allowing the occurrence of a potential sampling bias. Second, there was no common assessment of condition severity, which did not ultimately allow the adequate control of this variable in the analyses performed. Third, testretest reliability was not assessed for Kidcope in this study, even if such procedure has been recommended when using single items of the checklist (50). Fourth, even if such procedure has been generally adopted in previous studies using Kidcope, the thematic aggregation of health-related stressors was not as systematic as it would be if a formal qualitative content analysis procedure had been performed. Nevertheless, a number of strengths are to be equally acknowledged within this research study. The study "gave voice" to children and adolescents with chronic health conditions, instead of relying in proxy-reports that could not accurately depict the phenomenological experience of pediatric patients. Coping assessment was conducted in relation to a specific type of stressors and focused on discrete behaviors that can be trained and modified, as recommended for stress-coping research in pediatric psychology (51). Finally, the conduction of statistical analyses contrasted results from general and stratified clinical samples, thus evidencing developmental and clinical specificities, which could otherwise be overlooked.

In terms of clinical implications for pediatric practice, the results from this study suggest that health-related stressors should be 
screened in relation to specific chronic conditions, by taking in account that physical limitation and symptom interference stressors may be particularly relevant for patients with asthma, and psychosocial stressors more common in patients with neurodevelopmental conditions. As regards coping assessment, the examination of coping strategies utilization should be complemented with the analysis of their perceived efficacy, since pediatric patients may be prone to evaluate the effectiveness of their coping behaviors in relation to short-term consequences or maladaptive beliefs regarding oneself and one's tendencies for emotional regulation. In psychosocial or psychotherapeutic interventions targeting coping, results from the Kidcope checklist administration may assist the mapping of counterproductive coping responses, which, due to their specificity, may also facilitate the training and modification of coping strategies. In this sense, it is suggested that compassionate mind training, behavioral activation/social skills training, and mindfulness training may be viable therapeutic strategies to respectively target the coping responses of self-criticism, social withdrawal and externalizing emotional regulation, which have been observed to negatively correlate with pediatric HRQL outcomes.

Future research on pediatric health-related stress and coping should encompass variables that describe the social context in which the child/adolescent is embedded. Specifically, given the distinctive role of family and school contexts in children and adolescents' development, it is recommended that parental coping and school staff/peers' attitudes towards chronic health conditions and individuals living with them should be examined in relation to children/adolescents' coping and adaptation. Besides, it would be valuable to gain increased understanding on individual characteristics that may predispose an individual to adopt maladaptive coping strategies, such as low self-compassion and high psychological inflexibility, which could improve the depth of research and the effectiveness of stress-coping interventions in pediatric psychology.

\section{Conclusion}

The experience of health-related stressors and the utilization of coping strategies to deal with them are likely to vary across pediatric diagnoses. The variety and perceived efficacy of coping strategies used by children and adolescents with chronic health conditions generally portray a broad, flexible coping repertoire. Nevertheless, the coping strategies of externalizing emotional regulation and self-criticism are negatively linked to the HRQL of pediatric patients with asthma/epilepsy and cerebral palsy, respectively. In order to increase their effectiveness, pediatric stress-coping assessments and interventions should be sensitive to developmental and clinical specificities.

Acknowledgement: This study was supported by the R\&D Units "Institute of Cognitive Psychology, Vocational and Social Development" (PEst-OE/PSI/ UI0192/2011), and "Cognitive Behavioral Center for Research and Intervention" (PEst-OE/PSI/ UI0730/2014) of the University of Coimbra, by the Coimbra Cerebral Palsy Association, by the Calouste Gulbenkian Foundation (Ref. 96783 - AS), and by the Portuguese Foundation for Science and Technology (PhD Grants SFRH/BD/69885/2010; SFRH/ $\mathrm{BPD} / 70063 / 2010)$.

Authors' contributions. Conception and design: CC, MCC, LB; Acquisition, analysis and interpretation of data: CC, NS, HM, MCC; Drafting the article: CC, NS; Revising it critically for important intelectual content: LB, HM.

Conflict of interest: The authors declare that they have no conflict of interest.

\section{References}

1. Boekaerts M, Roder I. Stress, coping, and adjustment in children with a chronic disease: a review of the literature. Disabil Rehabil. 1999;21(7):311-37. 
2. Spirito A, Stark, LJ, Gil KM, Tyc VL. Coping with everyday and disease-related stressors by chronically ill children and adolescents. J Am Acad Child Adolesc Psychiatry. 1995; 34(3):283-90.

3. Immelt S. Psychological adjustment in young children with chronic medical conditions. J Pediatr Nurs. 2006;21(5):362-77.

4. Varni JW, Limbers CA, Burwinkle TM. Impaired health-related quality of life in children and adolescents with chronic conditions: a comparative analysis of 10 disease clusters and 33 disease categories/ severities utilizing the PedsQL 4.0 Generic Core Scales. Health Qual Life Outcomes 2007;5:43.

5. Compas BE, Jaser SS, Dunn MJ, Rodriguez EM. Coping with chronic illness in childhood and adolescence. Annu Rev Clin Psychol. 2012;8:455-80.

6. Moos RH. Life stressors, social resources, and coping skills in youth: applications to adolescents with chronic disorders. J Adolesc Health. 2002;30(4):22-9.

7. Eiser C. Psychological effects of chronic disease. J Child Psychol Psychiatry. 1990;31(1): 85-98.

8. Varni J, Wallander J. Pediatric chronic disabilities: hemophilia and spina bifida as examples. In: Routh D, editor. Handbook of Pediatric Psychology. N.Y.: Guilford; 1988. p. 190-221.

9. Schmidt S, Petersen C, Bullinger M. Coping with chronic disease from the perspective of children and adolescents-a conceptual framework and its implications for participation. Child Care Health Dev. 2003;29(1):63-75.

10. Petersen C, Schmidt S, Bullinger M, The DISABKIDS Group. Coping with a chronic pediatric health condition \& health-related quality of life. Eur Psychol. 2006;11(1):50-6.

11. Wallander JL, Varni JW, Babani L, Banis HT, Wilcox KT. Family resources as resistance factors for psychological maladjustment in chronically ill and handicapped children. J Pediatr Psychol. 1989;14(2):157-73.

12. Lazarus RS, Folkman S. Stress, appraisal, and coping. New York: Springer; 1984.

13. Compas BE, Connor-Smith JK, Saltzman H, Thomsen AH, Wadsworth ME. Coping with stress during childhood and adolescence: Problems, progress, and potential in theory and research. Psychol Bull . 2001;127(1):87-127.

14. Aaronson NK, Meyerowitz BE, Bard M, Bloom JR, Fawzy FI, Feldstein M, et al. Quality of life re- search in oncology: Past achievements and future priorities. Cancer. 1991;67(3):839-43.

15. Varni JW, Burwinkle TM, Lane MM. Health-related quality of life measurement in pediatric clinical practice: An appraisal and precept for future research and application. Health Qual Life Outcomes. 2005;9:1-9.

16. Harper D. Paradigms for investigating rehabilitation and adaptation to childhood disability and chronic illness. J Pediatr Psychol. 1991;16(5):533-42.

17. Bloomquist ML. Skills training for children with behavior problems: A parent and practitioner guidebook. New York: Guilford; 1996.

18. Carona C, Crespo C, Silva N, Lopes AF, Canavarro MC, \& Bullinger M. Examining a developmental approach to health-related quality of life assessment: Psychometric analysis of DISABKIDS generic module in a Portuguese sample. Vulnerable Child Youth Stud. 2013;8(3):243-57.

19. Cicchetti D. Development and psychopathology. In: Cicchetti D, Cohen DJ, editors. Developmental psychopathology. Volume 1: Theory and method. New York: Wiley; 2006, p. 1-23.

20. Stroud LR, Foster E, Papandonatos GD, Handwerger K, Granger DA, Kivlighan KT, et al. Stress response and the adolescent transition: performance versus peer rejection stressors. Dev Psychopathol. 2009;21(1):47-68.

21. Zimmer-Gembeck MJ, Skinner EA. The development of coping across childhood and adolescence: An integrative review and critique of research, Int J Behav Dev. 2011;35(1):1-17.

22. Spirito A. Common problems and coping strategies reported in childhood and early adolescence. J Youth Adolesc. 1991;20(5):531-44.

23. Austin J, Smith M, Risinger M, McNelis A. Childhood epilepsy and asthma: comparison of quality of life. Epilepsia. 1994;35(3):608-15.

24. LaGreca AM, Bearman KJ, Moore H. Peer relations of youth with pediatric conditions and health risks: promoting social support and healthy lifestyles. J Dev Behav Pediatr. 2002;23(4):271-80.

25. Quitmann J, Rohenkohl A, Specht A, PetersenEwert C, Schillmöller Z, Monika Bullinger. Coping strategies of children and adolescents with clinically diagnosed short stature. J Child Fam Stud. 2014 Apr 26. Epub 2013 Dec.

26. Malveaux, FJ. The state of childhood asthma: introduction. Pediatrics. 2009;123(3): S129- S30. 
27. Ronen GM, Streiner DL, Rosenbaum P. Healthrelated quality of life in childhood epilepsy: Moving beyond seizure control with minimal adverse effects. Health Qual Life Outcomes. 2003;1:36-46.

28. Moreno-De-Luca A, Ledbetter DH, Martin CL. Genetic insights into the causes and classification of the cerebral palsies. Lancet Neurol. 2012;11(3):283-92.

29. Raina P, O’Donnell M, Schwellnus H, Rosenbaum P, King G, Brehaut J, et al. (2004). Caregiving process and caregiver burden: conceptual models to guide research and practice. BMC Pediatr. 2004; $4: 1$.

30. Committee on Children with Disabilities, Committee on Psychosocial Aspects of Child and Family Health (CCD, CPACFH). Psychosocial risks of chronic health conditions in childhood and adolescence. Pediatrics. 1993;92(6):876-8.

31. Carona C, Silva N, Barros L, Canavarro MC. Portuguese versions of KIDCOPE instruments - Questionnaires for Coping Assessment in Children and Adolescents. The University of Coimbra; 2010. Unpublished manuscript.

32. Spirito A, Stark LJ, Williams C. Development of a brief checklist to assess coping in pediatric patients. J Pediatr Psychol. 1988:13;555-74.

33. Rodrigue JR, Geffken GR, Streisand RM. Child health assessment - A handbook of measurement techniques. Needham Heights, MA: Allyn \& Bacon; 2000.

34. The European DISABKIDS Group. The DISABKIDS Questionnaires - Quality of Life questionnaires for children with chronic conditions. Lengerich: Pabst Science Publishers; 2006.

35. Nunnally J, Bernstein IJ. Psychometric theory. 3rd ed. New York: McGraw-Hill; 1994.

36. Cohen J. Statistical power analysis for the behavioral sciences. Hillsdale, NJ: Erlbaum; 1988.

37. Cohen J. A power primer. Psychol Bull. 1992;112(1):155-9.

38. Simões M. Investigações no âmbito da aferição nacional do teste das Matrizes Progressivas de Raven [Raven's Progressive Matrices: Aferition studies]. Unpublished Doctoral Dissertation. The University of Coimbra, Portugal; 1994.

39. Global Initiative for Asthma [GINA]. Global strategy for asthma management and prevention - updated 2008. 2008; [cited 2014 Apr 26]. Available from http://www.ginasthma.org
40. Speechley KN, Sang X, Levin S, Zou GY, Eliasziw M, Smith ML, et al. Assessing severity of epilepsy in children: Preliminary evidence of validity and reliability of a single-item scale. Epilepsy Behav. 2008;13(2):337-42.

41. Surveillance of Cerebral Palsy in Europe (SCPE). Surveillance of cerebral palsy in Europe (SCPE): a collaboration of cerebral palsy surveys and registers. Dev Med Child Neurol. 2002;42(12):816-24.

42. Palisano R, Rosenbaum P, Bartlett D, Livingston M. Gross motor function classification system expanded and revised; 2007 [cited 2014 Apr 26]. Available from from http://motorgrowth.canchild. ca/en/GMFCS/resources/GMFCS-ER.pdf.

43. Arnaud C, White-Koning M, Michelsen SI, Parkes J, Parkinson K, Thyen U. Parent-reported quality of life of children with cerebral palsy in Europe. Pediatrics. 2008;121(1):54-64.

44. Campbell W, Missiuna C. Bullying risk in children with disabilities: a review of the literature. CANCHILD - Centre for Childhood Disability Research; 2011 [cited 2014 Apr 26]. Available from: http://www.canchild.ca/en/canchildresources/bullying_risk_children_disabilities.asp

45. Cheng S, Chan ACM. Factorial structure of the KIDCOPE in Hong Kong adolescents. J Genet Psychol. 2003;164(3):261-6.

46. Brossard-Racine M, Hall N, Majnemer A, Shevell MI, Law M, Poulin C, et al. Behavioral problems in school age children with cerebral palsy. Eur J Paediatr Neurol. 2012;16(1):35-41.

47. England MJ, Austin JK, Beck V, Escoffery C, Hesdorffer DC. Erasing epilepsy stigma: eight key messages. Health Promot Pract. 2014 [Epub ahead of print]

48. MacLeod JS, Austin JK. Stigma in the lives of adolescents with epilepsy: a review of the literature. Epilepsy Behav. 2003 4(2):112-7.

49. Gilbert P, Miles JNV. Sensitivity to social putdown: its relationship to perceptions of social rank, shame, social anxiety, depression, anger and selfother blame. Pers Individ Dif. 2000;29(4):757-74.

50. Spirito A. Pitfalls in the use of brief screening measures of coping. J Pediatr Psychol. 1996;21(4):573-5.

51. Blount RL, Simons LE, Devine KA, Jaaniste T, Cohen LL, Chambers C. Evidence-based assessment of coping and stress in pediatric psychology. J Pediatr Psychol. 2008;33(9):1021-45. 